\title{
Neoinstitucioalismo de Redes: precursores e trajetória da Rede ATER NE/Brasil ${ }^{1}$
}

\author{
Network Neoinstitucioalism: precursors and trajectory of the \\ ATER NE Network/Brazil
}

Neoinstitucioalismo de red: precursores y ruta de la Red ATER NE/Brasil

\author{
Marina de Sá Costa Lima \\ Gilberto Gonçalves Rodrigues ${ }^{3}$ \\ Sonia Maria Pessoas Pereira Bergamasco ${ }^{4}$
}

\section{Resumo}

LIMA, M. de S. C.; RODRIGUES, G. G.; BERGAMASCO, S. M. P. P. Neoinstitucioalismo de Redes: precursores e trajetória da Rede ATER NE/Brasil. Rev. C\&Trópico, v. 44, n.1, p. 163-189, 2020. DOI: https://doi.org/10.33148/cetropicov44n1(2020)art8

As Políticas Públicas para a Agricultura Familiar, por meio de estudos que envolvem a ação do Estado e a atuação de instituições de Assistência Técnica e Extensão Rural - ATER, juntamente com organizações não governamentais e de agricultores familiares, foram respaldadas pelo histórico de organizações da sociedade civil, pela democratização do país. O presente artigo tem como objetivo analisar o neoinstitucionalismo, em uma abordagem de redes, visando compreender a implementação da Política Nacional de Assistência Técnica e Extensão Rural-PNATER, por meio dos percursos e formação da Rede ATER Nordeste. Inicialmente, o debate da abordagem neoinstitucionalista ajuda a situar a atual análise sobre as instituições formais e informais, que se articulam em rede para os propósitos de implementação destas Políticas. Para finalizar, o enfoque da análise neoinstitucionalista de redes é refletido diante das condições e potencialidades frente à PNATER, por meio da recente experiência da Rede ATER NE no Brasil.

Palavras-Chave: Políticas Públicas. Assistência Técnica e Extensão Rural. Neoinstitucionalismo de Redes.

\footnotetext{
1 Agradecemos à Capes, por possibilitar a realização desta pesquisa; aos Professores Marcos Antônio Bezerra Figueiredo e Jorge Roberto Tavares de Lima; ao Centro de Desenvolvimento Agroecológico Sabiá, em especial, aos gestores Alexandre Henrique Pires e Maria Aureliano de Melo.

2 Doutora em Engenharia Agrícola - Planejamento e Desenvolvimento Rural Sustentável, Universidade Estadual de Campinas. Laboratório ARRE Água, Universidade Federal de Pernambuco. E-mail: marina.scl@gmail.com. Orcid: http://orcid.org/0000-0002-7497-5463.

3 Professor Doutor - Lab. ARRE Água, Centro de Biociências, Universidade Federal de Pernambuco. E-mail: gilbertorodrigues.ufpe@gmail.com. Orcid: https://orcid.org/0000-0002-4262-2903

4 Professora Titular da Faculdade de Engenharia Agrícola, Universidade Estadual de Campinas. E-mail: sonberg80@gmail.com. Orcid: https://orcid.org/0000-0002-9101-8278.
} 


\section{Abstract \\ LIMA, M. de S. C.; RODRIGUES, G. G.; BERGAMASCO, S. M. P. P. Network Neoinstitucioalism: precursors and trajectory of the ATER NE Network/Brazil. Rev. C\&Trópico, v. 44, n.1, p. 163-189, 2020. DOI: https://doi.org/10.33148/cetropicov44n1(2020)art8}

The Public Policies for Family Agriculture through studies involving State action and the work of institutions of Technical Assistance and Rural Extension - ATER, together with non-governmental organizations and family farmers, were supported by the history of civil society organizations, by the democratization of the country. This article aims to analyze the neoinstitutionalism in a networks approach, aiming understand of the implementation of the National Policy of Technical Assistance and Rural Extension - PNATER throughpathways and formation of the ATER Northeast Network. Initially, the debate on the neoinstitutionalist approach helps to situate the current analysis on formal and informal institutions, which are articulated in a network for the purposes of implementing these Policies. To conclude, the focus of the network neoinstitutionalist analysis is reflected in the conditions and potentialities front the PNATER, through the recent experience of the ATER Northeast Network.

Keywords: Public Policies. Technical Assistance and Rural Extension. Networks Neoinstitutional-ism.

\section{Resumen}

LIMA, M. de S. C.; RODRIGUES, G. G.; BERGAMASCO, S. M. P. P Neoinstitucioalismo de red: precursores y ruta de la Red ATER NE/Brasil. Rev. C\&Trópico, v. 44, n.1, p. 163-189, 2020. DOI: https://doi.org/10.33148/cetropicov44n1(2020)art8

Las políticas públicas para la agricultura familiar, a través de estudios que involucran la acción del Estado y el desempeño de las instituciones de Asistencia Técnica y Extensión Rural - ATER, junto con organizaciones no gubernamentales y de agricultores familiares, fueron respaldados por la historia de las organizaciones de la sociedad civil, para la democratización del país. Este artículo tiene como objetivo analizar el neoinstitucionalismo, en un enfoque de red, pretendiendo comprender la implementación de la Política Nacional de Asistencia Técnica y Extensión Rural-PNATER, a través de los caminos y la formación de la Red ATER Nordeste. Inicialmente, el debate sobre el enfoque neoinstitucionalista ayuda a situar el análisis actual sobre las instituciones formales e informales, que se articulan en una red con el propósito de implementación estas Políticas. Finalmente, el análisis neoinstitucionalista de las redes se refleja frente a las condiciones y el potencial que enfrenta PNATER, a través de la experiencia reciente de la Red ATER NE en Brasil.

Palabras clave: Políticas públicas, Asistencia Técnica y Extensión Rural, Neoinstitucionalismo de Redes.

Data de submissão: 20/04/2020

Data de aceite: 08/05/2020 


\section{Considerações iniciais}

Na reflexão sobre a ação do Estado ou dos governos, a expressão "neoinstitucionalismo" tem-se destacado desde a década de 1970 em países norte-americanos e europeus, como um tema de grande importância nas ciências agrárias e sociais (FREY, 2000; MARCH; OLSEN, 2008). Seu entendimento é essencial para a análise das políticas públicas, da forma como estas são implementadas e executadas pelas instituições. Em especial, a implementação de Políticas Públicas para a Agricultura Familiar veio conquistando uma efetividade no Brasil, nas duas últimas décadas, pela atuação em rede de instituições de Assistência Técnica e Extensão Rural (ATER), articuladas às organizações de agricultores familiares (ÁVILA et al., 2011; SABOURIN, 2014; GRISA; SCHNNEIDER, 2015).

Os debates sobre instituições, em como as ideias (valores) regem a construção de regras e normas, vêm influindo na formulação, gestão e implementação das políticas públicas (STEINMO, 2008). Muito se deve às mudanças e reforma na democratização do Estado em vários países, especialmente na América Latina (BERGAMASCO; NORDER, 2003). No Brasil, o processo de grande mobilização de diversos âmbitos da sociedade civil e da redemocratização, após a época ditatorial do Golpe de 1964, culminou em um importante marco: a promulgação da Constituição Brasileira de 1988, mudando o cenário político institucional (BERGAMASCO; NORDER, 2003; GRISA; SCHNNEIDER, 2015).

Vale salientar, como afirma Favareto (2010), que esse processo ocorreu devido ao fortalecimento da democracia, com um relativo grau de participação popular, enquanto base para as mais significativas mudanças no meio rural. Entre estas, a redução da pobreza e vulnerabilidade da população, com a inédita redução da desigualdade social e redução da fome, com mais segurança alimentar e soberania no campo. Uma experiência de crescimento econômico continuado para a agricultura familiar, com redistribuição de renda (direito constitucional ao amparo) e investimento político-institucional.

Por outro lado, Petersen e Almeida (2006) ainda reforçam a relevância das Comunidades Eclesiais de Base (CEBs) para o movimento agroecológico brasileiro. As CEBs, junto às organizações camponesas, impulsionaram a formação e atuação de diversas ONGs e diferentes instituições que, por sua vez, influenciaram redes de organizações, algumas das quais constituintes da Rede ATER NE. Muitas das práticas alternativas referenciadas na agroecologia são oriundas desses agricultores de base familiar e foram promovidas pelas CEBs. Nesse contexto, o neoinstitucionalismo de redes pode ser uma alternativa à compreensão exclusivamente das ações dos indivíduos e suas manifestações de interesses para outra concepção de instituições que gerem benefícios a ser compartilhados por todos (ou pela maioria) da comunidade. De acordo com Lima et al. (2011), as redes sociais, formais ou informais, representam uma categoria que pode influir diretamente na distribuição de poder, no fortalecimento de identidades e na defesa de interesses comuns resultantes das relações entre os atores. 
No caso da Rede ATER NE, foco desta pesquisa, Paranhos et al., (2007) reforçam o sentido de rede social entendida por um diálogo estabelecido entre o governo brasileiro junto a ONGs e movimentos sociais do campo, com ênfase na agricultura familiar e na concepção da agroecologia (princípio que rege sua identidade), reconhecendo o trabalho e acúmulos históricos dessas entidades. No entanto, questiona-se em que medida a formação de uma rede de extensão rural (formal ou informal) é necessária para a implementação da Política Nacional de Assistência Técnica e Extensão Rural - PNATER. Ao mesmo tempo, há uma interdependência entre instituições políticas e as demandas da sociedade civil, até mesmo entre as instituições políticas e socioeconômicas relativamente autônomas.

A Rede ATER NE foi constituída no Governo Luiz Inácio Lula da Silva, em 2004, como uma estratégia de ação da PNATER (2004). Atualmente, essa rede possui 13 entidades que assumem, como identidade de articulação, a perspectiva da agroecologia com ênfase no protagonismo do agricultor familiar. Em Pernambuco, a entidade responsável pela Rede ATER NE é o Centro de Desenvolvimento Agroecológico Sabiá, sujeito desta pesquisa, com 27 anos de fundação trabalhando os processos de construção coletiva de forma crítica à extensão rural convencional e se destacando na implementação de uma nova política de extensão rural agroecológica, adaptada ao Nordeste brasileiro. A agroecologia surge nas instituições de ATER como um marco, ao causar uma ruptura em diferentes modelos de atuação extensionista, predominando um enfoque na produção agrícola convencional ou, mais recentemente, valorizando uma produção agroecológica, mais adaptada ao ambiente e sensível ao processo de inclusão social da agricultura familiar para o bem comum (MUSSOI, 1985; CAPORAL, 2009; PETTAN, 2010).

Na valorização de um processo de bem estar coletivo, March e Olsen (2008) afirmam que considerar a importância do contexto social e histórico da política e dos motivos dos atores individuais faz do "novo institucionalismo" uma abordagem mais autônoma e descentralizada para as instituições. Diante dessa nova configuração, o presente trabalho tem o propósito de analisar o neoinstitucionalismo, em uma perspectiva de redes, visando proporcionar subsídios para a compreensão da implementação da Política Nacional de Assistência Técnica e Extensão RuralPNATER, por meio dos precursores (1950 a 2003) e da trajetória (2004 a 2016) de reconhecimento das ONGs que compõem a Rede ATER NE.

Todavia, determinar um período temporal específico para os precursores desta Rede é sempre complexo por se tratar de processos sociais, com rupturas e continuidades. Assim, uma atenção será dada ao modo como estes referenciais precursores foram construídos, em alguns momentos chaves, nas suas relações com a dinâmica social e entre o Estado. Para elucidar as questões e o propósito enunciados, as perspectivas de análise estão inseridas em uma abordagem multidimensional de construção de uma análise da PNATE. Os principais conceitos utilizados foram o neoinstitucionalismo de redes e as redes sociais (STEINMO, 2008; ELIAS, 1994). 
Para tanto, a pesquisa baseou-se na análise exploratória de um estudo de caso, realizado com cinco extensionistas e gestores do Centro de Desenvolvimento Agroecológico Sabiá (criado em 1993, um dos primeiros constituintes da Rede ATER NE), situado no município de Rio Formoso e na cidade de Recife, em Pernambuco. Previamente aprovada, a pesquisa está registrada no Comitê de Ética em Pesquisa (CEP), da Universidade Estadual de Campinas, a partir do CAAE 80667317.2.0000.5404

O Centro Sabiá foi selecionado para a pesquisa, representando a Rede ATER $\mathrm{NE}$, devido aos seguintes critérios: ter boa representatividade em número de famílias beneficiadas de Pernambuco, cerca de 3.000 famílias; atuar em diferentes regiões da zona da mata, agreste e sertão, abrangendo 53 municípios; trabalhar com os biomas diferenciados, a Mata Atlântica e a Caatinga; incluir um público beneficiário bastante heterogêneo da agricultura familiar (assentados, quilombolas, pescadores, ribeirinhos, comunidades rurais). Para além das ações e atividades desenvolvidas, o Centro Sabiá foi um dos primeiros componentes da Rede ATER NE.

Os extensionistas foram abordados por meio de entrevistas informais e posteriormente, semiestruturada, entre os anos de 2016 e 2018, com um formulário de questões e roteiros dirigidos sobre a estrutura, gestão e atuação do Centro Sabiá, enquanto instituição e enquanto componente da Rede ATER NE, servindo à análise do processo de formação e consolidação dessa Rede. Complementarmente, uma análise mais complexa foi realizada no sentido de aprofundar os anseios dos extensionistas diante de sua realidade em constantes mudanças e adaptações por meio de relatos de suas trajetórias e do Centro Sabiá (MINAYO, 2017).

A primeira parte da pesquisa apresenta uma problematização, trazendo referenciais do neoinstitucionalismo de redes. A seguinte parte aborda um aprofundamento da importância da noção de redes sociais para a geração de políticas de extensão rural para a agricultura familiar. Na terceira seção, o percurso de articulação de redes sociais das ONGs e a incidência na Política Nacional de Assistência Técnica e Extensão Rural (PNATER) expressa a construção de novas potencialidades de atuação das Políticas Públicas. A pesquisa é finalizada com algumas considerações sobre a pertinência desses referenciais e as formas de relações estabelecidas entre sociedade civil e Estado.

\section{Neoinstitucionalismo de rede}

A compreensão do "Neointitucionalismo", como uma perspectiva teórica, não pode ser baseada em uma abordagem científica única ou unificada, especialmente por se referir às diferenças de contextos, de questionamentos e problemas que o norteiam, bem como a análise metodológica (HALL; TAYLOR, 2003).

Segundo Lima et al., (2011), a inclusão do conceito de redes na abordagem Neoinstitucionalista se deu em consequência do entendimento das redes enquanto instituições, apresentando modelos frequentes de interações e trocas entre as pessoas e suas organizações, formais ou informais. Nesta linha de pensamento, mantém-se 
a forte influência do Institucionalismo histórico, acumulando, assim, a categoria de redes enquanto um fator que influi diretamente na distribuição de poder, no fortalecimento de identidades e na defesa de interesses resultantes das relações entre os atores.

As redes constituem uma velha forma de organização social que remete a outros tipos de sociedades ou de sociabilidades, sistemas de trocas, comunicação, de organização da produção e do comércio (CASTELLS, 2000). Esse autor reforça que a característica principal das redes se dá nos fluxos de pessoas, objetos, informações, símbolos, em diversos contextos sociais, tempos e espaços diferenciados, como também nas formas de organização de determinados grupos humanos.

Os estudos neoinstitucionalista de redes envolvem linhas de pensamento que vão desde um enfoque relacional das ações políticas e socioeconômicas até a complexa rede de interações que compreendem os indivíduos, os grupos e as organizações sociais. Mais ainda, as redes possibilitam a análise de um processo dinâmico intrínseco, ao mobilizar informações, recursos, conhecimentos e saberes.

A partir do momento em que as entidades representativas se assemelham em suas trajetórias, elas vão tornando-se cada vez mais interrelacionadas em redes e, desta forma, o neoinstitucionalismo de redes pode proporcionar subsídios para uma melhor compreensão das relações complexas entre organizações, inseridas em um determinado contexto sociopolítico, cultural, econômico e ambiental. As principais pesquisas nesta área abrangem diferentes perspectivas, dentre elas: relação entre diversos grupos sociais; redes públicas; dinâmicas de mercado; movimentos sociais; e implementação de Políticas Públicas (SCHERER-WARREN, 2006; LIMA et al., 2011).

$\mathrm{Na}$ presente pesquisa, as contribuições do neoinstitucionalismo de redes vão fornecer elementos importantes para as análises de Políticas para a Agricultura Familiar. Entre eles, a noção da relação entre as novas redes instituídas e suas relações com a organização social dos agricultores, que contribuem para fortalecer a sua atuação na implementação das Políticas Públicas para a Agricultura Familiar.

\section{O papel das Redes Sociais}

Os estudos sobre redes sociais envolvem a emancipação da sociedade civil, a gestão social solidária, a economia solidária e a democracia participativa (MARTINS, 2004). Gramisci (2001) nos fornece elementos para compreender a emancipação da sociedade civil, na relação com o Estado. A aprendizagem de uma socialização da política, com a ampliação e abertura institucional, constitui uma "sociedade regulada" com a transformação dos interesses privados para a constituição de uma dimensão pública que expressa a vontade coletiva na construção de um projeto de sociedade, para um Estado social do trabalho e da solidariedade.

Neste sentido, Singer (2002a) entende a economia solidária como uma forma antagônica de organização da economia em relação aos modelos de mercantilização de acumulação do capital. De acordo com o autor, a economia solidária reflete outro modo de produção, baseados nas tomadas de decisões coletivas (organização social), 
mantendo o direito à liberdade individual, refletindo numa redistribuição solidária da renda que necessita de mecanismos estatais.

Através da gestão social solidária, a emancipação humana é alcançada, no processo democrático deliberativo (tomadas de decisões coletivas) e dialógico, baseando no entendimento, na argumentação e não na negociação estritamente utilitária do termo. Com a participação efetiva no processo de tomada de decisão, a democracia participativa possibilita o crescimento e amadurecimento para os atores envolvidos (FREIRE, 1997).

Na presente pesquisa, a análise da Rede ATER NE visa a compreender não apenas os fatores formais que propiciaram a sua constituição, enquanto parte das metas da PNATER, mas, sobretudo, como e o que levou essas organizações a se juntarem para formar uma rede de extensão rural, a qual atua articuladamente com outras redes de entidades da agricultura familiar e outras organizações não governamentais.

Algumas pesquisas tendem a reproduzir, de certa forma, um aspecto comum, ao considerar a rede social como algo simples, ou seja, uma relação estabelecida entre diversos elementos através de conexões que trocam informações entre si, podendo multiplicar-se em novos elementos (MANCE, 2001; MARTINS, 2004). Para um maior aprofundamento teórico, faz-se necessário incluir as dimensões históricas, culturais e simbólicas no estudo, como bem apontam Bourdieu (1999) e Latour (2005).

De modo geral, há os estudos que utilizam a noção de redes para descrever as novas mobilizações sociais e práticas cotidianas (DAVILA, 1992; MANCE, 2001); os antigos e os novos arranjos de poder (MACÍAS, 2002); e as mudanças no mundo do trabalho (MOLINA, 1995). Outros estudos vão além de aplicar uma ideia simplista de rede, buscando aprofundar o contexto para teorizar, com o propósito de intervir na realidade social (BOURDIER, 1999; LATOUR, 2005). A compreensão de redes sociais passa a ser concebida como sistemas complexos que funcionam articulados por agências humanas e indivíduos. Neste cenário, destacam-se os estudos sobre as redes sociotécnicas (CALLON, 1989; CASTELLS, 2000; LATOUR, 2005).

No caso brasileiro, há um enfoque e uma aplicação dos estudos de redes pelas políticas públicas e por novas formas de gestão do Estado. Alguns autores aplicam o conceito de redes sociais com o propósito de planejamento e intervenção na agricultura (ABRAMOVAY, 2000) e nas políticas de saúde (FLEURY; DUVERNEY, 2007; LIMA et al., 2011). Na área da saúde, as políticas públicas receberam uma nova designação por Fleury e Duverney (2007), com o termo de "redes de políticas", que representam os novos arranjos organizacionais policêntricos que decorrem dos processos de descentralização da área de saúde no Brasil.

Em nível mundial, Martins (2004) demonstra como a sociedade civil exige cada vez mais respostas das políticas locais para a conquista e o usufruto dos direitos da cidadania, com mais agilidade e eficácia. A redefinição de ideia de "direitos", partindo da concepção de "um direito a ter direitos", inclui a invenção de novos direitos, emergentes de lutas específicas e de suas práticas concretas. É o caso do direito à cidadania que requer a constituição de sujeitos sociais ativos, os agentes políticos, determinando 
o que consideram ser seus direitos (não pelo viés da classe dominante) e seu reconhecimento enquanto tais (uma estratégia dos não-cidadãos) (DAGNINO, 2004).

Neste âmbito, os anseios da sociedade civil e governamental, com intelectuais e técnicos, inserem-se no debate sobre redes sociais ao envolver a construção de políticas que enfatizem a participação social e as ações de descentralização dos serviços públicos, incluindo os serviços de ATER, saúde, educação, acesso à terra, uso sustentável dos recursos naturais, dentre outros (BERGAMASCO, 1993; CAPORAL, 2009). Há diversos significados que podem ser reconhecidos no conceito de redes sociais. Para Castells (2000), as redes constituem uma velha forma de organização social que remete a outros tipos de sociedades ou de sociabilidades, sistemas de trocas, comunicação, de organização da produção e do comércio. Há concepções de redes sociais que dão ênfase às estratégias individuais dos atores sociais na construção de laços sociais fortes, ainda que parcialmente influenciado pela estrutura (ELIAS, 1994). Estes laços possuem um papel fundamental para resistir a situações sociais adversas, tais como a seca, o desemprego, a falta de pagamento, em relação ao peso que teria alguns fatores estruturais e coletivos (GRANOVETTER, 1983).

A presente pesquisa considera o conceito de redes sociais de Nobert Elias (1994), o qual propõe a noção de uma rede em constante movimento, como um conceito para explicar a dinâmica de relações humanas, a qual não é reduzida à liberdade individual, nem ao constrangimento coletivo. A rede em movimento se refere a um "tecer e destecer" ininterrupto das relações, como bem descreve o mesmo autor: "Assim, efetivamente cresce o indivíduo, partindo de uma rede de pessoas que existiam antes dele, para uma rede que ele ajuda a formar" (ELIAS, 1994, p. 34).

A noção de rede social ainda é carregada de uma série de debates, apesar do reconhecimento teórico e metodológico, trazendo à tona alguns questionamentos, relacionados à proposta deste artigo, qual seja,no debate contemporâneo das ciências sociais e agrárias que entende o novo institucionalismo como uma perspectiva histórica e atuação em rede sociais, de forma que a importância das instituições se revela nas normas sociais que governam cotidianamente a vida e as interações sociais. Desta forma, a implementação de uma política pública deve ser explicada pela sua capacidade de inserção cultural no decorrer do tempo, ao levar em conta o potencial endógeno - de baixo para cima, "botton up", dos sujeitos da pesquisa.

\section{Precursores e a trajetória da Rede ATER NE}

Nesta seção, serão analisados os antecedentes e os percursos das organizações que propiciaram a formação das organizações que recentemente constituem a Rede ATER NE, com uma especial atenção ao Centro Sabiá. À princípio, algumas organizações iniciais serão tratadas, dentre elas, as Comunidades Eclesiais de Base (CEBs), associações de trabalhadores rurais, a Federação de Órgãos para Assistência Social e Educacional (FASE), o Projeto Tecnologias Alternativas (PTA), a Rede PTA, a Assessoria e Serviços a PTA (AS-PTA), o Movimento de Agricultura Alternativa 
(MAA), os Centros de Tecnologias Alternativas (CTAs). Em seguida, algumas entidades da trajetória da Rede ATER NE serão abordadas, com especial atenção ao Centro de Desenvolvimento Agroecológico Sabiá, enquanto componente desta rede.

No Brasil, o histórico das redes de extensão rural, de base agroecológica, tiveram suas raízes nas associações de trabalhadores rurais, ainda na década de 1940 (FERNANDES, 2000; LIMA, 2018), e nas atuações das Comunidades Eclesiais de Base (CEBs) (PETERSEN; ALMEIDA, 2006). De acordo com Fernandes (2000) as associações posteriormente conhecidas como "ligas camponesas", surgiram pontualmente em diferentes regiões, mas foi bastante expressiva no estado de Pernambuco, em 1955, com a criação da Sociedade Agrícola e Pecuária de Plantadores de Pernambuco (SAPPP). A mobilização pelo direito à terra, autoconsumo e a reprodução social contribuiu na expansão para outras regiões do Brasil, sendo referência pela luta por melhores condições de vida.

Ao longo da década de 1960, a FASE (fundada em 1961) atuou fortemente, com associativismo e cooperativismo, contando com um grande apoio das CEBs, a qual tinha sede em praticamente todos os estados do Brasil. Trabalho este surpreendido pelo Golpe de 1964, passando a atuar na resistência à ditadura e na formação dos movimentos comunitários de base e das frentes sindicais (FASE, 2013). Neste período (1960-1970), a FASE foi reduzindo as áreas atendidas com os frequentes cortes orçamentários e restrições sofridas. Ainda hoje, a sua atuação e desempenho na defesa dos diretos territoriais dos povos tradicionais, como as populações indígenas e os remanescentes de quilombo tem uma grande repercussão (LIMA, 2018).

Após as perseguições dos trabalhadores rurais na Ditadura Militar, os movimentos sociais se reorganizaram e fundaram a Confederação Nacional dos Trabalhadores na Agricultura - CONTAG, em 1963, agregando os sindicatos rurais. Frente às atrocidades no campo, o movimento passou a ter respaldo da igreja católica, representada pela Confederação Nacional dos Bispos do Brasil - CNBB e pela Comissão Pastoral da Terra - CPT.

Em meados da década de 1970, diante da miséria, expulsão e migração de milhares de camponeses, as atuações das CEBs emergiram aderindo às reivindicações das famílias de agricultores por reforma agrária e direito à vida no campo, diante das consequências socioambientais, da concentração de terras, Revolução Verde, desmatamento acelerado e do controle repressivo do Estado (BERGAMASCO; NORDER, 2003; MONTEIRO; LONDRES, 2017).

Petersen e Almeida (2006) demonstram o papel das Comunidades Eclesiais de Base (CEBs) como um dos maiores precursores para o movimento agroecológico brasileiro. No final da década de 1970, haviam cerca de 80 mil Comunidades Eclesiais de Base (BETTO, 1985). Em 1975, a Comissão Pastoral da Terra (CPT) surge e se estabelece num processo de mobilização junto aos camponeses em vários estados (MONTEIRO; LONDRES, 2017).

Uma forte participação da sociedade civil organizada foi, igualmente, fundamental na construção dessa nova visão da Assistência Técnica e Extensão Rural 
(ATER) (PETTAN, 2010). A atuação da Federação Nacional dos Trabalhadores da Assistência Técnica e do Setor Público Agrícola (FASER), da CONTAG, do Movimento dos Trabalhadores Rurais Sem Terra (MST), de associações e cooperativas de trabalhadores rurais, dentre outros movimentos sociais do campo, como o Grito da Terra e integrantes das universidades que focavam ações para a agricultura familiar, na abordagem do humanismo crítico, educação popular e agroecologia (PICOLOTTO, 2009; LIMA, 2018;).

Com a redemocratização, na década de 1980, as organizações dessas famílias e as CEBs passaram a formar articulações, agregando sinergias às mobilizações, com fortes críticas à expropriação camponesa no Brasil (MONTEIRO; LONDRES, 2017), às propostas de mercantilização dos bens comuns e da natureza (FASE, 2013), o uso exacerbado de fertilizantes químicos e agrotóxicos, a perda da diversidade biológica (PETERSEN; ALMEIDA, 2017). Período este que viabilizou a formação e consolidação de diversas redes de entidades de assessoria a esses agricultores, bem como a reorganização dos movimentos populares, em nível nacional (BERGAMASCO et al., 2015).

Entre 1970 e 1980, com a problemática ambiental ganhando visibilidade, diversas iniciativas de tecnologias alternativas à agricultura industrial passam a ganhar forma, financiadas pela cooperação internacional. Nesse bojo, inicia-se a época da "agricultura alternativa", a qual deu origem a diferentes correntes de pensamento. Um dos projetos iniciais foi a criação do Projeto Tecnologias Alternativas (PTA), em 1983, conquistando experiências agrícolas, mais adaptadas ao ambiente, com participação comunitária e a parceria institucional da FASE (PTA/FASE) (MONTEIRO; LONDRES, 2017). Posteriormente, essas experiências serviram para consolidar a Rede PTA, no ano de 1988.

Ao trazer um histórico do movimento agroecológico no Brasil, Costa et al., (2015) também revelam o início da trajetória da Rede PTA da Fase, relatando abaixo:

Em 1983 se constituía o Projeto de Tecnologias Alternativas da Federação de Órgãos para a Assistência Social e Econômica PTA/FASE, que posteriormente viria dar origem à Assessoria e Serviços a Projetos em Agricultura Alternativa AS-PTA. Organizado por profissionais que retornavam do exílio na Europa, o PTA passou a atuar junto a movimentos sociais do campo, em distintas regiões do país. Significativos aportes foram dados pela AS-PTA nos campos da informação e capacitação de recursos humanos, na articulação interna do Movimento de Agricultura Alternativa - MAA e com movimentos afins da América Latina e Europa, na mediação para e, ou, viabilização de recursos de agências financiadoras e filantrópicas européias para as ONGs do setor, na internalização da discussão do padrão tecnológico e da agricultura alternativa nos movimentos sociais do campo 
que, até então, se pautavam pelas lutas e reivindicações nas esferas das políticas agrária e agrícola, e de apoio à produção em moldes convencionais (COSTA et al., 2015).

Segundo o autor, o MAA surge através de estudantes e profissionais de agronomia, ciências agrárias, para incentivar a formação de grupos de agricultura alternativa, contando com o apoio e articulação da AS-PTA. Esta última também passa a fazer assessorias metodológicas para os Centros de Tecnologias Alternativas (CTAs), dos quais surgiram diversas ONGs autônomas, tais como: o CTA, de Ouricuri/PE; o PTABahia; e o CTA Montes Claros.

Para situar este momento, o Movimento de Agricultura Alternativa (MAA), com o aprofundamento da crise socioambiental no padrão de modelo agrícola brasileiro, passou a internalizar os princípios e as ideias da agroecologia principalmente após a AS-PTA Agricultura Familiar e Agroecologia (uma associação de direito civil sem fins lucrativos) lançar, em 1989, o livro, traduzido do inglês "Agroecologia: As Bases Científicas da Agricultura Alternativa" de Miguel Altieri (publicado originalmente nos EUA em 1983) (COSTA et al., 2015).

Mais adiante, alguns CTAs deram origem a outras organizações não-governamentais, de forma que: o CTA de Ouricuri/PE passou a ser Centro de Assessoria e Apoio aos Trabalhadores e Instituições não Governamentais Alternativas (Caatinga); o PTA/Bahia formou o Serviço de Assessoria a Organizações Populares Rurais (Sasop); e o CTA Montes Claros, o Centro de Agricultura Alternativa (CAA) do Norte de Minas Gerais (MONTEIRO; LONDRES, 2017).

Para Costa et al., (2015), as linhas de trabalho dos CTAs eram baseadas na demonstração, avaliação e sistematização de experiências, com atividades de editoração e difusão dos conhecimentos apreendidos e experiências dos (e para) técnicos, agricultores e suas organizações. Dentre os CTAs, dois deles atualmente são entidades que compõem a Rede ATER NE, a Caatinga e o Sasop. A Rede ATER NE é constituída pelas seguintes entidades abaixo, da Tabela 1:

Tabela 1: Entidades que constituem a Rede ATER NE.

\begin{tabular}{|c|c|c|c|c|}
\hline Entidades & $\begin{array}{c}\text { Estados } \\
\text { de atuação }\end{array}$ & $\begin{array}{l}\text { No previsto } \\
\text { de famílias }\end{array}$ & $\begin{array}{c}\text { No de } \\
\text { municípios }\end{array}$ & Territórios de abrangência \\
\hline $\begin{array}{l}\text { Centro } \\
\text { Sabiá }\end{array}$ & $\mathrm{PE}$ & 800 & 10 & Sertão do Pajeú e Mata Sul \\
\hline Diaconia & PE e RN & 1.500 & 4 & $\begin{array}{c}\text { Sertão do Pajeú (PE) e Apodi } \\
(\mathrm{RN})\end{array}$ \\
\hline MOC & BA & 2.250 & 10 & Sisal \\
\hline Ascoob & BA & 900 & 8 & $\begin{array}{c}\text { Bacia do Jacuípe, Paraguassu, } \\
\text { Litoral Norte e Recôncavo }\end{array}$ \\
\hline $\begin{array}{l}\text { Apaeb - } \\
\text { Valente }\end{array}$ & BA & 900 & 16 & Sisal e Bacia do Jacuípe \\
\hline
\end{tabular}




\begin{tabular}{|c|c|c|c|c|}
\hline Caatinga & $\mathrm{PE}$ & 1.000 & 9 & Sertão de Araripe \\
\hline Patac & $\mathrm{PB}$ & 995 & 11 & Cariri e Seridó \\
\hline AS-PTA & $\mathrm{PB}$ & 1.500 & 13 & Borborema \\
\hline Cepac & PI & 720 & 6 & Carnaubais \\
\hline Sasop & BA & 840 & 7 & $\begin{array}{l}\text { Baixo Sul e Sertão do } \\
\text { São Francisco }\end{array}$ \\
\hline Cetra & $\mathrm{CE}$ & 800 & 4 & Itapipoca \\
\hline Esplar & $\mathrm{CE}$ & 800 & 7 & $\begin{array}{l}\text { Sertão Central, Sobral e } \\
\text { Inhamuns }\end{array}$ \\
\hline Assocene & $\begin{array}{c}\text { SE, AL, PE, } \\
\text { PB, RN, } \\
\text { NA, PI }\end{array}$ & 845 & 14 & $\begin{array}{l}\text { Apodi (RN), Cariri e Mata (PB), } \\
\text { Mata Sul e Agreste Meridional } \\
\text { (PE), Sertão Central (AL), } \\
\text { Sertão Ocidental (SE) }\end{array}$ \\
\hline Totais & 9 & 3.850 & 120 & 29 \\
\hline
\end{tabular}

Fonte: Paranhos et al., (2007).

Segundo Lima (2018), outra ONG antiga de referência, em Pernambuco, é o Centro Josué de Castro (1979) que emergiu nos percursos dos CTAs. Criada por pesquisadores pernambucanos de Universidades, o Centro Josué de Castro adotou como referência a influência do humanismo vinculado a uma perspectiva ativista, crítica e comprometida com a transformação da realidade, contra as causas que geram a fome e a pobreza no mundo.

As estratégias dos PTAs representam uma importante iniciativa que se submete a processos de avaliação por cooperações internacionais. Algumas experiências se baseavam em conhecer as áreas de manejo dos agricultores, a diversidade de plantas, a variedade de animais criados, bancos de sementes, associações com espécies arbóreas (agrofloresta de caráter tradicional), mutirões, acessando o potencial endógeno da região, com experiências que potencializam a transição agroecológica. Como essa abordagem requer uma atuação profunda, baseada em processos dialógicos com as comunidades locais, na prática, os PTAs não tiveram apoio institucional necessário para ampliar essas experiências em termos quantitativos (LIMA, 2018; CENTRO SABIÁ, 2018).

A diversificação de práticas de manejo e diversidade agrícola foram realizadas nas propriedades com os agricultores familiares, tais como construir sistemas agroflorestais, tecnologias de captação de água, manejo ecológico, micro-irrigação e construção de barreiro trincheira. Em meados da década de 1980 à década de 1990, a cooperação internacional impulsionou a ideia e práticas de intercâmbios entre grupos de técnicos e agricultores, do Brasil para a Nicarágua (CENTRO SABIÁ, 2018). 
No decorrer da década de 1990, com as fronteiras agrícolas de commodities se expandiam e continuaram causando recorrentes expropriações de pequenos agricultores e o desmatamento acelerado nos biomas do Brasil. Uma problemática que só aumentou a dimensão ética e crítica de enfrentamento a esse modelo hegemônico na agricultura. Segundo Bergamasco e Norder (2003), um período fortemente influenciado pelo processo de redemocratização do país que, após vinte anos da ditadura militar, volta a buscar outros tipos de desenvolvimento, que incluíssem os povos do campo e fossem ambientalmente mais duráveis (PETERSEN; ALMEIDA, 2006; CAPORAL, 2009; LIMA, 2018).

Dentre os movimentos sociais, a década de 1990 ainda foi marcada por forte mobilização pela terra, liderada pelo Movimento dos Trabalhadores Rurais Sem Terra (MST), pelos movimentos sindicais dos trabalhadores rurais - a Federação dos Trabalhadores na Agricultura do Estado de Pernambuco (Fetape) e por outras tantas organizações existentes no estado (SIGAUD et al., 2008). Diante da crise sucroalcooleira na zona da mata pernambucana, essas organizações acabavam fazendo "o papel do Estado" em garantir o acesso à terra aos trabalhadores do campo, realizando acampamentos em latifúndios, passíveis de desapropriação pelo o Estatuto da Terra (1964).

Nesse contexto de forte dimensão política, mais precisamente entre o final de 1980 e o início de 1993, a ideia de criação do Centro Sabiá ganha força, por meio de um grupo de pessoas envolvidas com pesquisa e universidade. Quando, em 9 de julho de 1993, é fundado o Centro de Desenvolvimento Agroecológico Sabiá, como muitas organizações na sociedade civil neste início de década, segundo Gonçalves e Santos (2018). Uma análise mais detalhada acerca desta ong será realizada no tópico seguinte.

O Centro Sabiá é uma organização não governamental, cuja sede principal está localizada em Recife, Pernambuco, no Nordeste do Brasil. O seu princípio maior é de promover a agricultura familiar, sob as bases da agroecologia. Como "missão institucional", o Cento Sabiá declara "plantar mais vida para um mundo melhor, desenvolvendo a agricultura familiar agroecológica e a cidadania” (CENTRO SABIÁ, 2018). O desafio desta missão é gerar vínculos com os diferentes setores da sociedade civil, resgatando experiências e saberes locais ao desenvolver tecnologias inovadoras, incluindo o potencial endógeno do núcleo familiar, das comunidades e territórios.

Nos países da América Central, Nicarágua, Honduras e Guatemala, as pesquisas realizadas, com base em centros especializados da experiência "campesino a campesino", método sociotécnico inovador e diferenciado que se propaga rapidamente, inspirou o Centro Sabiá a iniciar os seus trabalhos, como o caso da abordagem de agricultor difusor e, de outras organizações, o de agricultor experimentador (CENTRO SABIÁ, 2018). Segundo um Gestor do Centro Sabiá:

Bom, e aí o próprio trabalho do Centro Sabiá também nasce dessa perspectiva, que é o que a gente chamava de agricultor difusor. Também reproduzindo a ideia de difusão tecnológica, da agricultura convencional, da assistência técnica convencio- 
nal que outras organizações chamam de agricultores experimentadores. Mas essa experiência está baseada na concepção do campesino a campesino, que é dos agricultores compreenderem, entenderem, vivenciar e praticar e a partir disso poder disseminar esses conhecimentos com outros agricultores. Não desenvolvendo um papel técnico, de assistência técnica, que não deixa de ser... (GESTOR DO CENTRO SABIÁ, 2017).

No mesmo ano de fundação, o Centro Sabiá participa de um encontro em Tauá, no Ceará, a convite do Sindicato dos Trabalhadores Rurais e da Esplar (ONG que atua no semiárido cearense) e atualmente é componente da Rede ATER NE. O encontro fazia parte da capacitação de Ernest Gotsch, agricultor e pesquisador suíço reconhecido pela agricultura sintrópica e agrofloresta (CENTRO SABIÁ, 2018). Quando a equipe do Centro Sabiá retorna da capacitação em sistemas agroflorestais, seus membros resolvem realizar imediatamente o manejo recém aprendido. $\mathrm{O}$ fato foi retratado na seguinte entrevista:

Já nesse ano, no final de noventa e três, participa um grupo de pessoas da equipe e de agricultores com quem o grupo Sabiá trabalhava, participa, em Tauá no Ceará, a convite do Sindicato dos Trabalhadores Rurais, de uma capacitação com Ernest Gotsch, que era o suíço agricultor, que tinha toda a técnica da agrofloresta. Então o grupo vai pra lá, quando volta, volta com a cabeça doida de alegria dizendo que o Centro Sabiá tinha que trabalhar com sistema agroflorestal (GESTOR DO CENTRO SABIÁ, 2017).

Uma etapa especial nesse percurso foi a internalização do conceito de "agroecologia”, uma vez que ainda não era um tema amplamente conhecido e assimilado por algumas organizações sociais no Nordeste, mesmo as mais consolidadas (CENTRO SABIÁ, 2018). Embora muito de suas atuações já seguissem passos fundamentais de bases agroecológicas, sem denomina-las dessa forma. Fundamental para esta compreensão da concepção da agroecologia foi a participação de organizações da Rede PTA no Consórcio Latinoamericano de Agroecologia e Desenvolvimento Sustentável (Clades), no início dos anos de 1990, mudando efetivamente seus enfoques de trabalho (GONÇALVES; SANTOS, 2018, CENTRO SABIÁ, 2018).

Nesta pesquisa, a agroecologia é compreendida como uma ciência que propõe compreender a complexidade dos agroecossistemas, por meio de: um olhar crítico aos métodos difusionistas de tecnologia (agrotóxicos, fertilizantes, transgênicos); entender a organização e manejo de agroecossistemas que se constituem, partindo dos "sistemas agrícolas tradicionais", ao reconhecer saberes tradicionalmente construído por 
esses mantenedores dos agroecossistemas (agricultores e comunidades tradicionais); criando um diálogo de saberes com os fundamentos e métodos científicos construídos nas instituições de ensino, pesquisa e extensão; contribuindo na transformação social, com o protagonismo e direito desses agricultores (PETERSEN; ALMEIDA 2006; TOLEDO; BARRERA-BASSOLS, 2008).

Tida como uma ciência pós-normal emergente, a agroecologia para Toledo e Barrera-Bassols (2008) possui três pilares indissolúveis - numa "trilogia sagrada", sendo definida como: 1. uma ciência que tem como premissa básica o diálogo de saberes na construção do conhecimento agroecológico, integrando o conhecimento acadêmico (interdisciplinar) e os saberes-práticas dos povos e comunidades camponesas/tradicionais; 2. um hábito, prática ou modo de vida dessas populações que praticam uma agricultura diversificada, de base familiar; 3. como um movimento social, incluindo as demandas dos povos do campo, promovendo justiça e equidade social.

Portanto, o papel da Rede PTA e seus programas de desenvolvimento local emergem formando redes locais (formais e informais) de agroecologia ao abranger sindicatos, associações comunitárias, grupos de mulheres, grupos da igreja (GONÇALVES; SANTOS, 2018). Segundo os autores, estas redes e articulações de experiências locais de agroecologia precisavam urgentemente de um espaço de concertação nacional que reconhecesse a diversidade de estratégias das atuações agroecológicas para catalisar o diálogo com frentes governamentais.

Consequentemente, ainda na década de 1990, no intuito de fortalecer a urgência de uma articulação em âmbito nacional, a AS-PTA e a Embrapa Agrobiologia organizaram o "I Encontro Nacional de Pesquisa em Agroecologia”, em 1999. Por outro lado, no mesmo ano, o Fórum Brasileiro de ONGs e Movimentos Sociais para o Meio Ambiente e Desenvolvimento e o Fórum Nacional de Reforma Agrária realizaram o "Seminário sobre Reforma Agrária e Meio Ambiente". Esses encontros possibilitaram reforçar a proposta de um evento maior, no Brasil, capaz de reunir as experiências das organizações sociais atuantes na agroecologia (GONÇALVES; SANTOS, 2018).

Em decorrência dessas demandas, representantes de diversas redes locais, regionais e nacionais, de intuições governamentais e lideranças de movimentos sociais realizaram o I Encontro Nacional de Agroecologia (I ENA), em 2002. Os desdobramentos deste encontro concretizou um amplo vínculo das redes estaduais e regionais de agroecologia, bem como deu origem à Articulação Nacional de Agroecologia (ANA) (GONÇALVES; SANTOS, 2018). Em seguida, este fato implicou em recorrentes debates preparatórios sobre agroecologia, para a realização de diversos seminários, fóruns em todo o Brasil (PETERSEN; ALMEIDA, 2017). A busca pela superação de problemas e gargalos na concepção e implementação das políticas públicas para agricultura familiar é tema de debate frequente, não apenas neste espaço político, mas também fazem parte das articulações das organizações locais, onde as políticas são implementadas. 


\section{A trajetória da Rede ATER NE (2004 a 2018)}

Antes de adentrar nos caminhos da Rede ATER NE, faz-se necessário esclarecer o debate institucional que envolveu a proposta de concretizar uma nova política de ATER, pública e universal.

O ponto inicial, para Bergamasco et al., (2015), ocorreu durante o "Seminário Nacional de Assistência Técnica e Extensão Rural - Uma nova extensão para a agricultura familiar”, organizado pela FASER, CONTAG e a Associação Brasileira de Entidades Estaduais de Assistência Técnica e Extensão Rural (ASBRAER), em Brasília no ano de 1997. Nesta ocasião, vieram à tona a retomada dos debates que envolvem o papel da ATER pública, fundamentada no humanismo e movimento agroecológico enquanto bases para sua operacionalização. Contudo, o evento que se destacou, no mesmo ano - "Workshop Uma Nova Assistência Técnica e Extensão Rural Centrada na Agricultura Familiar", foi organizado pela FASER, CONTAG, ASBRAER, MAA e Programa das Nações Unidas para o Desenvolvimento (PNUD). Este evento proporcionou um modelo de ATER direcionado, exclusivamente, à agricultura familiar, que fosse disponibilizado de forma gratuita aos beneficiários, financiado com recursos públicos, mas que fosse permitido a prestação dos serviços de ATER por ONGs, como associações e cooperativas de agricultores, mantendo as empresas ou instituições públicas (BERGAMASCO et al., 2015).

Ainda, em 2002, houve uma série de ciclos de seminários regionais, organizados pela FASER e a CONTAG para discutir a PNATER (BERGAMASCO et al., 2015). Por outro lado, havia fundamentalmente a pressão das atividades inovadoras das ONGs, algumas trazendo experiências dos antigos Conselhos Eclesiais de Base (CEBs), atuação dos movimentos sociais e integrantes das universidades que mantinham suas ações prioritariamente para a agricultura familiar, em uma perspectiva da agroecologia (COSTA et al., 2015).

$\mathrm{O}$ intuito era construir princípios que aderissem ao pluralismo na prestação serviços, para poder incluir as especificidades das populações tradicionais, como as indígenas e quilombolas. Com amplos seminários organizados, a finalidade era de promover políticas que focassem na agricultura familiar, abrangendo ações de base agroecológica, com questões de gênero, etnia e juventude, ou seja, um serviço de qualidade a ser prestado de forma gratuita, universal e continuada.

Por fim, em 2004, o Governo Federal cria a PNATER representando uma conquista de espaço institucional, decorrente destes fóruns, seminários e debates da sociedade civil organizada, organizações locais e instituições governamentais, após a histórica pressão desses movimentos na realidade do meio rural no Brasileiro (PETTAN, 2010; BERGAMASCO et al., 2015). Oficialmente, os princípios e diretrizes que regem a ATER no Brasil estão fundamentados em três pilares centrais: a exclusividade da agricultura familiar como público beneficiário; atuar mediante processos educacionais dialéticos, com metodologias participativas; e a ênfase na abordagem agroecológica (LIMA, 2018). 
A PNATER foi o fator que impulsionou a criação institucional da Rede ATER NE, ainda em 2004, no governo do presidente Luiz Inácio Lula da Silva. Sob a responsabilidade do Ministério do Desenvolvimento Agrário (MDA), a PNATER traz princípios e diretrizes que visam a orientar os serviços de ATER para garantir o fortalecimento da agricultura familiar, enquanto setor público no Brasil. Pela primeira vez, um governo brasileiro cria um aparato institucional para a construção de uma extensão rural voltada unicamente a um público historicamente excluído, o agricultor familiar, traçando influências na constituição de abordagens dialéticas e práticas participativas, trabalhando o reconhecimento de diferentes grupos de populações tradicionais e suas diferentes culturas e etnias, trazendo igualmente a visibilidade do papel da mulher nessas comunidades (CNM, 2015). Essa é a trajetória inicial da constituição da PNATER, a promessa de um espaço institucional para dar suporte as atuações inovadoras em redes de extensão rural, principalmente no âmbito das Ongs, como bem relata um Gestor do Centro Sabiá:

Com a PNATER e a presença de algumas pessoas que eram das organizações sociais, dentro do Governo Federal, do MDA, especificamente, se viu que havia uma possibilidade de, com a PNATER, que as organizações pudessem acessar recursos dessa política nacional de ações técnicas e extensão rural. Mesmo que ela não tivesse se transformado, naquele momento, em lei, que só acontece em 2010. Então essa história da PNATER foi a grande motivação. Nós juntamos, com um grupo de organizações. Inicialmente Centro Sabiá, Diaconia, MOC, Patac e Cetra (GESTOR DO CENTRO SABIÁ, 2017).

Para traçar planos para uma nova política de ATER, cada organização passou a expor um pouco sobre suas experiências, acúmulo de conhecimentos, linhas de atuação, concepções envolvendo extensão rural e agroecologia para discutir as propostas, tanto individual como coletivamente das ações, numa etapa preliminar da formação da Rede ATER NE (LIMA, 2018).

O espaço institucional de concertação envolvendo o governo e as ONGs já vinha sendo construído e reconhecido em outras ocasiões de ações de ATER, em rede, na área rural com os agricultores familiares. É o caso de organizações como a Diaconia, o Centro de Desenvolvimento Agroecológico Sabiá, o Caatinga, o Movimento de Organização Comunitária (MOC), o Programa de Aplicação de Tecnologia Apropriada às Comunidades (Patac) e o Centro de Estudos do Trabalho e de Assessoria ao Trabalhador (Cetra) (PIRES, 2011; CENTRO SABIÁ, 2018).

Anteriormente, o Centro Sabiá já havia participado de outras reuniões com essas organizações, em Recife, para discutir a elaboração de uma proposta de projeto sobre assistência técnica e extensão rural articulada ao Governo. Essa articulação foi consolidada para elaborar estratégias de extensão rural de formação e capacitação, 
de fundos solidários e de construção de tecnologias sociais, via acesso ao recurso da Sudene. O Cetra, no Ceará, é um exemplo de organização que promoveu o acesso ao recurso e contou com a parceria das outras organizações do Nordeste para a gestão desse recurso (LIMA, 2018).

A trajetória em conjunto dessas ongs facilitou a constituição das organizações que iriam participar, mais adiante, da Rede ATER NE. Portanto, em 2004, essas organizações são chamadas, agora por meio da PNATER, para diálogo e acordos que desencadearam na origem da Rede. Um outro aspecto relevante é que essas organizações, incluindo o Centro Sabiá, já faziam parte da Articulação do Semiárido (ASA), um processo conhecido como "redes de redes": articulações entre redes, de acordo com Castells (2000).

Como a ASA, o Centro Sabiá é uma ampla rede que abrange diversas outras redes, convergindo em atuações na convivência com o semiárido (foco específico da ASA), nas práticas de Sistemas Agroflorestais (SAFs), na adaptação aos biomas da Mata Atlântica e Caatinga, ou seja, linhas que estão inseridas e atuam em uma base agroecológica. Desse conjunto de redes atuais, somam-se os caminhos já percorridos da Rede PTA, que gerou a Articulação Nacional de Agroecologia (ANA), da qual algumas das organizações da Rede ATER NE também fazem parte nos dias de hoje (CENTRO SABIÁ, 2018; COSTA et al., 2015). Atualmente, O Centro Sabiá, enquanto ONG, faz parte da ASA, da ANA, do Processo de Articulação e Diálogo (PAD), da Rede de Agroecologia da Mata (RAMA) e da Rede de Assistência Técnica e Extensão Rural do Nordeste (Rede Ater NE) (CENTRO SABIÁ, 2018). Essta configuração em articulações de diferentes redes sociais, em variados níveis (local à nacional), com intercâmbios e trocas de experiências entre as mesmas, vem potencializando os benefícios dessas interações, bem demonstradas em outro relato, a seguir:

Bom, da Rede PTA, que deu origem à ANA, lá em 2002. Então assim, você tem um conjunto, embora algumas não estão nesse espaço da Rede PTA e outras não estão no espaço da ASA. Mas de toda forma essas organizações elas não surgem do nada. Esses três ambientes, de certa forma, é o que converge a ideia de convidar essas organizações pra essa conversa, essa reunião para a formação da Rede ATER NE. Daí cada organização montou um projeto individualmente (GESTOR DO CENTRO SABIÁ, 2017).

A etapa seguinte das organizações foi demonstrar suas experiências, elaborando projetos e definindo a localidade do trabalho, o público selecionado, as temáticas específicas etc. (PARANHOS et al, 2007). Segundo Gestor do Centro Sabiá (2017): “Na época, em termos de financiamento, as organizações da Rede ATER NE receberam do governo cerca de 250 mil reais, cada uma, para um projeto anual. Desse total, o recurso para as ações coletivas das organizações atingia cerca de 30 mil." 
No caso do Centro Sabiá, o recurso coletivo foi disponibilizado para a produção de um jornal, denominado Gente da Terra, com o objetivo de divulgar as experiências das organizações da Rede. Não se tratava de um jornal do exclusivo do Centro Sabiá e sim da Rede ATER NE. Desta forma, cada organização geriu seu recurso, destinado ao coletivo, em uma área própria de referência, como agroecologia ou formação sobre economia solidária (PARANHOS et al, 2007). Na $3^{\text {a }}$ edição do Jornal, o registro completo do II Encontro Nacional de Agroecologia - ENA de 2006, em Recife, foi realizado enfatizando o processo de mobilização e sistematização das experiências e atuações de transições agroecológicas da Rede no Nordeste (ANA; FASE, 2014).

Do ponto de vista da concepção metodológica, que envolve a troca de experiências e o acúmulo de conhecimentos de forma coletiva, é válido ressaltar a importância da ideia e e das práticas de intercâmbio. $\mathrm{O}$ intercâmbio foi uma experiência inicialmente desenvolvida pela antiga Rede PTA e foi incorporada pelo Centro Sabiá e pela Rede ATER NE como um todo (demais entidades).

A Caatinga, ONG da Rede ATER NE, por exemplo, desenvolveu um trabalho denominado Projeto Campo Ativo, que tinha a estratégia de organizar um grupo de jovens (25 pessoas) chamado de Agentes Promotores da Agroecologia (APAs). Como bem demonstra o entrevistado:

Eles construíram a ideia de formar esse grupo de vinte e cinco jovens, com técnicas de abordagem, de como pensar a convivência com o semiárido, a agroecologia, etc. De plantio agrícola, de comercialização, de beneficiamento, de debate sobre políticas públicas, manejo da caatinga, tinham vários aspectos. E esses jovens assessoravam e acompanhavam grupos de agricultores nas suas próprias comunidades. Essa experiência, foi uma experiência que o coordenador do Caatinga teve quando visitou a Nicarágua, conheceu essa experiência, e quando foi a construção do projeto, eles idealizaram fazendo as adaptações para a nossa realidade (GESTOR DO CENTRO SABIÁ, 2017).

Este fato evidencia como a construção das metodologias, hoje internalizadas pela Rede ATER NE, vieram de uma forma "Botton Up", oriundas das experiências das próprias Ongs, entre extensionistas e agricultores, nas constantes trocas de experiências, em diferentes níveis, do local ao internacional. A Rede ATER NE incorporou a prática de intercâmbio porque as próprias organizações dessa Rede vêm dessa mesma trajetória.

March e Olsen (2008) reforçam que a tendência descentralizada de funcionamento das instituições e a atuação mais autônoma, como no caso desta Rede extensionista, reflete no que representa o "novo institucionalismo". Para Bergamasco (1993), a 
descentralização dos serviços públicos, em especial, os de Extensão Rural é a base para a participação social nas políticas públicas.

Em termos de diretrizes do Centro Sabiá, um Gestor afirma que a Comunicação precisa ser compreendida e realizada por todos da equipe, porque se refere à dimensão central das ações da Ong. Dela decorrem todas as relações entre os técnicos, entre técnicos e agricultores e entre os próprios agricultores (GESTOR DO CENTRO SABIÁ, 2017). Ao fazer referência a Paulo Freire, um dos Gestores traz a ideia de mudança no entendimento da extensão rural como uma assistência técnica para uma proposta inovadora de comunicação e extensão baseada na obra de Freire.

Outra diretriz do Centro Sabiá é a da economia solidária, das relações econômicas na construção de mercados mais horizontais. Para um dos Gestores, a agroecologia é o paradigma adotado pelo Centro Sabiá e um princípio maior que norteia toda ação do Centro Sabiá, seja no sentido de reconhecer, valorizar e estimular os saberes dos agricultores e agricultoras, como um fator essencial. O papel das mulheres é mais um princípio trabalhado pela Ong, principalmente para poder entender como as agricultoras se tornam indutoras de processos de desenvolvimento agroecológico.

Como programas específicos, o Centro Sabiá tem um primeiro "Programa Agrofloresta e Economia Solidária" que é trabalhado em três dimensões, a Agrofloresta, a Economia Solidária e a Segurança Alimentar e Nutricional. O segundo programa se refere ao "Programa Comunicação para Mobilização Social", para acessar as famílias mais isoladas e frequentemente invisibilizadas do meio rural. No terceiro, o "Programa Gestão e Desenvolvimento Institucional" visa a atuação em gestão compartilhada, exercitando mecanismos democráticos de participação. O "Programa Políticas Públicas e Desenvolvimento Territorial” é o quarto programa que trata de contribuir na construção das Políticas públicas para agricultura familiar, incluindo populações tradicionais (CENTRO SABIÁ, 2018).

Ainda há o quinto "Programa Convivência com o Semiárido e Sustentabilidade Ambiental" para dar suporte às adaptações das famílias de agricultores ao semi-árido, com estratégias de manejo da agrobiodiversidade. Por fim, o sexto é o "Programa Direitos Humanos na Agricultura Familiar Camponesa”, no intuito contribuir no empoderamento de mulheres, jovens, negros e negras, indígenas e LGBT do campo (CENTRO SABIÁ, 2018).

Dentro do programa sobre direitos humanos, é trabalhada uma abordagem diferenciada nas ações do Centro Sabiá, tanto para o reconhecimento das mulheres enquanto sujeito de direitos próprios, quanto para a valorização da juventude do meio rural. Ainda neste programa, trabalham-se as ações de direito dos remanescentes de quilombos, de populações indígenas, pescadores, ribeirinhos e demais populações tradicionais. Reconhece que esses grupos socialmente diferenciados, também são sujeitos das políticas públicas para agricultura familiar e de assistência técnica e extensão rural, é respaldar os princípios da agroecologia, de inclusão social e produtiva. 
Esses programas são denominados “programas da ação fim”, quando o trabalho é realizado direto com o público. Nos outros programas, de Direito à Comunicação para Mobilização Social e o programa de Gestão e Desenvolvimento Institucional, são mais direcionados para a própria estrutura interna, do cuidado da instituição do Centro Sabiá.

Em um primeiro momento, cada organização elaborou um projeto e depois se depararam com uma condição, a Rede ATER NE enquanto um espaço institucional de concertação entre as organizações envolvidas. No início, esse processo de constituição da Rede e o seu papel perante as organizações não estavam tão claros (PARANHOS et al., 2007). Segundo um dos Gestores:

Como a gente é rede, se cada um tem um projeto? Claro que isso era importante porque a relação com o estado é institucional. Então sendo de uma institucionalidade, você não pode responder pelo outro. Então cada organização teria, de fato, o seu convênio direto com o MDA. Mas aí nós realizamos um primeiro encontro, que foi em Afogados da Ingazeira, em 2004, de formação da Rede ATER NE, onde cada organização indicou a participação de três pessoas, por organização. E nós conseguimos que, nesse processo de formação, que nós tivéssemos vários dirigentes das suas organizações, no sentido de ajudar a dar uma certa direção política também (GESTOR DO CENTRO SABIÁ, 2017).

No processo de formação, as organizações perceberam a fragmentação de ideias, no momento inicial, e descartaram a abordagem proposta para construir um programa que serviu para todos da Rede ATER NE, do ponto de vista de concepção política. A partir dessa iniciativa, as atividades que estavam presentes nos projetos das organizações deram suporte ao novo programa (ANA; FASE, 2014)

Desta forma, em cada território, foi realizado um primeiro momento de formação, por exemplo, no território do Sertão do Pajeú-PE, e as outras etapas (módulos) de formação, ocorreram em territórios distintos no Nordeste, com o intuito de que todas as organizações pudessem circular no território de atuação das outras entidades da Rede ANA; FASE, 2014).

A base do processo de formação consistia, segundo um Gestor do Centro Sabiá, em ir diretamente para as experiências dos agricultores, entender como os agricultores e as agricultoras desenvolviam os seus sistemas agrícolas, de forma a contribuir com uma base agroecológica (CENTRO SABIÁ, 2018). Portanto, ao invés de abordar os agricultores, teorizando sobre agroecologia ou extensão rural, o Centro Sabiá buscava a experiência concreta do trabalho que os agricultores estavam fazendo, em um diálogo e trocas com eles nesse momento. 
O papel do Neoinstitucionalismo de Redes e a noção de redes sociais para a compreensão da implementação da PNATER, por meio da Rede ATER NE, se deve a dois fatores essenciais. Um deles foi o comprometimento das entidades em trabalhar com os agricultores familiares, como sujeitos políticos do processo de transição agroecológica. Estes atributos são responsáveis pelo estabelecimento da rede e da constituição de sua identidade institucional (PARANHOS et al., 2007). O consenso das organizações em partir de uma perspectiva agroecológica, para se trabalhar a sustentabilidade dos sistemas agrícolas, é um fator chave na trajetória da rede.

As relações construídas nos intercâmbios representam um elemento de grande influência no levantamento de ideias, princípios, valores e experiências em comum que constituem uma identidade de rede (PARANHOS et al., 2007). Por outro caminho, estes vínculos têm a capacidade de atuar com um efeito sinérgico, multiplicando suas atuações pelas redes locais, regionais e estaduais, na troca de experiências agroecológica nos diferentes níveis.

Como bem constatam Latour (2005) e Castells (2000), as redes sociotécnicas funcionam em uma articulação entre agências humanas (e não humanas) e indivíduos. Para Elias (1994), nesse processo constante e dinâmico das relações em rede, em movimento, é quando o indivíduo se fortalece devido a uma articulação anterior de pessoas, uma trajetória que serve de base a nova rede que ele passará a construir.

A Rede ATER Nordeste possui uma ampla atuação junto as entidades participantes, com o apoio do Programa Nacional de ATER (Pronater) em cerca de 16 mil famílias agricultoras, localizadas em 120 municípios, de 29 territórios, abrangendo nove estados no Nordeste. As redes locais/regionais são formadas por instituições, formais e informais, como organizações dos agricultores, ONGs, pastorais, igrejas, universidades, extensionistas, dentre outros (PARANHOS et al., 2007).

Ao priorizar o enfoque da agroecologia, observou-se a atuação da Rede ATER NE como mediadora dinâmica e abrindo mais um espaço para a interação entre diversos grupos de agricultores familiares, de redes sociais e organizações nos estados nordestinos. Do mesmo modo, esta rede extensionista atua na construção de vínculos com outras redes locais e microrregionais, ao mesmo tempo em que faz parte ativamente das grandes redes estaduais e nacionais.

Portanto, o enfoque da análise do novo institucionalismo, com foco em redes, no caso das entidades que compõem a Rede ATER NE, vem funcionando no intuito acabar com o isolamento social dos agricultores através da interação, do reconhecimento de seus conhecimentos, experiências, adaptações e inovações locais, diante dos demais, principalmente com outros agricultores, além dos técnicos. Nesta lógica, o técnico atua como um mediador, um ator social que detém um conhecimento tão importante quanto o dos agricultores

Importa ainda reforçar que a trajetória da Rede ATER NE tem, no aspecto da comunicação, um papel importante que fortalece a socialização dos saberes 
tradicionais que constituem conhecimentos agroecológicos, construídos na ação coletiva de técnicos e agricultores em rede. O conhecimento acumulado é transmitido a um conjunto maior de técnicos que se apropriam do processo de aprendizagem dialética. Portanto, a comunicação, em seu diálogo com as redes locais/ microrregionais, estaduais e nacionais, fortalece a expressão da rede como ator político frente à sociedade.

\section{Considerações Finais}

A princípio, algumas considerações poderão ser afirmadas ao trazer o enfoque da análise neoinstitucionalista de redes. As entidades que compõem a Rede ATER NE têm como intuito fundamental acabar com o isolamento social dos agricultores na interação, por meio do reconhecimento de seus conhecimentos, experiências e adaptações locais, principalmente com outros agricultores, além dos técnicos. Nesta lógica, o técnico atua como um ator social que detém um conhecimento tão importante quanto o dos agricultores.

As experiências dos agricultores também são impulsionadas pela dinâmica da rede, nos intercâmbios e nas trocas entre pessoas de diferentes localidades, abrindo um espaço para que ocorram processos de construção de conhecimentos agroecológicos, de forma mais aberta e horizontal. Portanto, o intercâmbio é a base para o estabelecimento de um movimento social que gera inovação agroecológica, por meio de sistemas formais e informais de comunicação.

A contribuição da Rede para os objetivos da PNATER se dá na participação social, na construção conjunta com entidades, extensionistas e agricultores, e na oportunidade de propor mudanças na política para o fortalecimento dos agricultores familiares e das redes locais na construção de conhecimentos agroecológicos. Deste modo, a reflexão de como e em que medida a Rede se percebe como ator desta política, especialmente trazendo sistematizada as suas atuações inovadoras em campo é uma forma de gerar subsídios para a práxis da Política de ATER.

Na pesquisa, a PNATER foi capaz de ser estabelecida de forma "Botton up", de baixo para cima, ao se constituir desde o início por entidades de ATER que já trabalhavam em parcerias entre si. Aproveitando a rede informal que já havia se concretizado para, em seguida, se transformar em uma rede formalizada: a Rede ATER NE. O estabelecimento da Rede formal ampliou os espaços de concertação com representantes de organizações dos agricultores familiares, reforçando o seu papel enquanto sujeito político. 


\section{Referências}

ABRAMOVAY, R. A rede, os nós, as teias: tecnologias alternativas na agricultura. $\boldsymbol{R} \boldsymbol{e}$ vista de Administração Pública. v. 34, n. 6, 2000.

ANA, ARTICULAÇÃO NACIONAL DE AGROECOLOGIA; FASE. FEDERAÇÃO DE ÓRGÃOS PARA A ASSISTÊNCIA SOCIAL E EDUCACIONAL. Caderno Pedagógico: Agroecologia, desenvolvimento territorial e políticas públicas; Articulação Nacional de Agroecologia; Federação de Órgãos para a Assistência Social e Educacional - Rio de Janeiro, ANA / FASE, 2014, 96 p.

ÁVILA, M. L. de; SABOURIN, E. P.; DUARTE, L. M. G.; MASSADIER, G. ATER e desenvolvimento territorial: Uma análise crítica. Revista de Extensão e Estudos Rurais, v. 1, n. 2, p. 427-448. 2011.

BERGAMASCO, S.M.P.P. Extensão Rural: passado e presente no discurso e na prática. In: CORTEZ, L.A.B.; MAGALHÃES, P.S.G. (Coord.). Introdução à engenharia agrícola. 2.ed. Campinas: Editora da UNICAMP, p.353-364. 1993.

BERGAMASCO, S.M.P.P. et al. Evaluation of Extension Reforms in Brazil. Relatório Parcial. IFPRI. 2015.

BERGAMASCO, S.M.P.P.; NORDER, L.A.C. A alternativa dos assentamentos rurais: organização social, trabalho e política. São Paulo: Terceira margem, 2003. 191p.

BOURDIEU, P. Las formas de capital. Lima: Piedra Azul, 1999.

BETTO, F. O que é comunidade eclesial de base: primeiros passos. São Paulo: Abril Cultural; Brasiliense, 1985.

CALLON, M. La science et ses réseaux. Gènese et circulation des faits scientifiques. Paris: La Découverte; Conseil de l'Europe; UNESCO, 1989.

CAPORAL, F.R. Extensão Rural e Agroecologia: temas sobre um novo desenvolvimento rural, necessário e possível. Brasília: 398, 2009.

CASTELLS, M. A sociology of the network society. In: Contemporary - A Journal of reviews. v. 29, n.5, ASA., pg.693-699, 2000.

CENTRO DE DESENVOLVIMENTO AGROECOLÓGICO SABIÁ - Centro Sabiá. 2018.

CONFEDERAÇÃO NACIONAL DE MUNICÍPIOS - CNM. $2 \boldsymbol{a}$ Conferência Nacional de Assistência Técnica e Extensão Rural na Agricultura Familiar e na Reforma Agrária: Etapa Local. Brasília: CNM, 2015.60 p.

COSTA, M.B.B. et al. Agroecologia no Brasil - 1970 a 2015. Agroecología, v.10, n. 2, p. 63-75, 2015. 
DAGNINO, E. Sociedade civil, participação e cidadania: de que estamos falando? IN: MATO, D. (Coord.) Políticas de ciudadanía y sociedad civil en tiempos de globalización. Caracas: FACES, Universidad Central de Venezuela, p. 95-110, 2004.

DAVILA, I. Nada de soledades: algunas notas sobre redes sociales entre mujeres. El casco antiguo de Alicante. Revista del Instituto Alicantino de Cultura. v. 24, n.23, p.199-208, 1992.

ELIAS, N. A sociedade dos indivíduos. Rio: Jorge Zahar, 1994

FEDERAÇÃO DE ÓRGÃOS PARA ASSISTÊNCIA SOCIAL E EDUCACIONAL FASE. Visões alternativas ao Pagamento por Serviços Ambientais. Rio de Janeiro: Núcleo Justiça Ambiental e Direitos - FASE, 2013, 80p.

FAVARETO, A. As políticas de desenvolvimento territorial rural no Brasil em perspectiva - uma década de experimentações. Desenvolvimento em Debate, v.1, n.2, p.47-63, 2010.

FERNANDES, Bernardo Mançano. A formação do MST no Brasil. Rio de Janeiro: Vozes, 2000.

FLEURY, S.; DUVERNEY, A.M. Gestão de redes: a estratégia de regionalização da política de saúde. Rio de Janeiro: Ed. FGV, 2007.

FREIRE, P. Pedagogia da autonomia: saberes necessários à prática educativa. São Paulo: Paz e Terra. 1997.

FREY, K. Políticas públicas: um debate conceitual e reflexões referentes à prática da análise de políticas públicas. Planejamento e políticas públicas, v.21, p.211-259, 2000.

GONÇALVES, A.L.; SANTOS, A.C. Caminhos para a construção de sistemas alimentares sustentáveis. Alemanha: MISEREOR, 2018.

GRAMSCI, A. Cadernos do cárcere. Os intelectuais. O princípio educativo. Jornalismo. Volume 2, Rio de Janeiro: Civilização Brasileira, 2001.

GRANOVETTER, M. The strenght of weak ties: a network theory revisited. Sociological Theory. v.1, p.201-233, 1983.

GRISA, C.; SCHNEIDER, S. Três gerações de políticas públicas para a agricultura familiar e formas de interação entre sociedade e Estado no Brasil. In: GRISA, C.; SCHNEIDER, S (Orgs.) Políticas públicas de desenvolvimento rural no Brasil. Porto Alegre: Editora da UFRGS, p. 19-50, 2015.

HALL, P; TAYLOR, R. As três versões do neo-institucionalismo. Lua Nova, n. 58, p.193$224,2003$.

LATOUR, B. Reassembling le social: An introduction to Actor-Network-Theor. Oxford: Oxford University Press, 2005. 
LIMA, L.D.; MACHADO, C.V.; GERASSI, C.D. O neo-institucionalismo e a análise de políticas de saúde: contribuições para uma reflexão crítica. In: MATTOS, R. A. caminhos para análise das políticas de saúde, p.111-137, 2011.

LIMA, M.S.C. A Rede ATER Nordeste: participação e conflitos de interesses no processo de implementação da Política Nacional de Assistência Técnica e Extensão Rural (PNATER). 2018. Tese (Doutorado em Engenharia Agrícola) - Faculdade de Engenharia Agrícola, Universidade Estadual de Campinas, São Paulo.

MACÍAS, A.G. Redes sociales y clusters empresariales. REDES - revista hispana para el análisis de redes sociales. v.1, n.6, p.1-20, 2002.

MANCE, E. A revolução das redes. A colaboração solidária como uma alternativa pós-capitalista à globalização atual. 2.ed.. Petrópolis: Vozes, 2001

MARCH, JG; OLSEN JP. Neo-institucionalismo: fatores organizacionais na vida política. Revista Sociologia e Política, v. 16, n. 31, p. 121-142, 2008.

MARTINS, P.H. As redes sociais, o sistema da dádiva e o paradoxo sociológico. Caderno CRH, Salvador, v. 17, n. 40, p. 33-48, 2004.

MINAYO, M. C. de S. Amostragem e saturação em pesquisa qualitativa: consensos e controvérsias. Revista Pesquisa Qualitativa, v. 5, n. 7, p. 01-12, 2017.

MOLINA, J. L. Análisis de redes y cultura organizativa: una propuesta metodológica. Revista Española de Investigaciones Sociológicas. n.71/72, p.249-263, 1995.

MONTEIRO, D.; LONDRES, F. Pra que a vida nos dê flor e frutos: notas sobre a trajetória do movimento agroecológico no Brasil. In: A Política Nacional de Agroecologia e Produção Orgânica no Brasil: uma trajetória de luta pelo desenvolvimento rural sustentável. Brasília: Ipea, p. 53-83, 2017.

MUSSOI, E.M. Extensão rural: uma contribuição ao seu repensar. Revista Centro de Ciências Rurais, v. 1, n.15, p. 37 - 50, 1985.

PARANHOS, M.G.; SILVEIRA, L.M.; NOUGUEIRA, F. A trajetória da Rede ATER Nordeste: construindo conhecimento agroecológico pelo Nordeste brasileiro. In: Articulação Nacional de Agroecologia, Construção do Conhecimento Agroecológico: Novos Papéis, Novas Identidades. p. 56-70, 2007.

PETERSEN, P.; ALMEIDA, S. G. Rincões transformadores: trajetória e desafios do movimento agroecológico brasileiro - uma perspectiva a partir da Rede PTA. Rio de Janeiro: AS-PTA, 2006. 54 p.

PETTAN, K.B. A Política Nacional de Assistência Técnica e Extensão Rural (PNATER): percepções e tendências. 2010. Tese (Doutorado em Engenharia Agrícola) - Faculdade de Engenharia Agrícola, Universidade Estadual de Campinas, São Paulo. 
PICOLOTTO, E.L. A emergência dos “agricultores familiares" como sujeitos de direitos na trajetória do sindicalismo rural brasileiro. Mundo Agrário, v. 9, n. 18, 2009.

PIRES, A.H. Extensão Rural, Agroecologia e Juventude Rural: A experiência dos Agentes Promotores da Agroecologia (APAS), no Sertão do Araripe - Pernambuco. 2011. Dissertação (Mestrado em Extensão Rural e Desenvolvimento Local), Universidade Federal Rural de Pernambuco, Recife.

SCHERER-WARREN, I. Das mobilizações às redes de movimentos sociais. Soc. estado. v.21, n.1, p.109-130, 2006.

SIGAUD, L.; ROSA, M.; MACEDO, M.E. Ocupações de Terra, Acampamentos e Demandas ao Estado: Uma Análise em Perspectiva Comparada. Revista de Ciências Sociais, v. 51, n. 1, p. 107 a 142, 2008.

SINGER, P. Introdução à Economia Solidária. São Paulo: Fundação Perseu Abramo, 2002a.

STEINMO, S. Historical institutionalism. In: DELLA PORTA, D; KEATING, M (Eds) Approaches and Methods in the Social Sciences. Cambridge: Cambridge University Press, p. 113-138. 2008.

TOLEDO, V.M.; BARRERA-BASSOLS, N. La Memoria Biocultural: la importancia ecológica de las sabidurías tradicionales. Barcelona: ICARIA Editorial, 232p., 2008. 
